\title{
TRASPASAR LOS LÍMITES DE LA MUERTE: EL AMOR EN GABRIEL MARCEL Y VIKTOR FRANKL Sandra Ruiz Gros*
}

RESUMEN: La muerte, sea la propia o la del ser amado, nos provoca incertidumbre, malestar y dolor, pero no por ello dejamos de pensar y de buscar alivio y consuelo. Con este fin, se revisa el pensamiento de dos autores contemporáneos, Gabriel Marcel y Viktor Frankl. Ambos conocieron de cerca el dolor por la muerte del ser amado y ambos respondieron de la misma manera: a través del amor.

PALABRAS CLAVE: Amor, dolor, esperanza, muerte, misterio, problema, vida, Gabriel Marcel, Viktor Frankl.
KEYWORDS: Love, pain, hope, death, mystery, problem, life, Gabriel Marcel, Viktor Frankl. 


\section{TRASPASAR LOS LÍMITES DE LA MUERTE: EL AMOR EN GABRIEL MARCEL Y VIKTOR FRANKL}

\section{El signo de la muerte en el pensamiento de Gabriel Marcel}

El talante sosegado y cálido del matrimonio Marcel-Boegner hacía que las puertas de su casa en la Rue Vernont y el castillo de Le Peuch estuvieran siempre abiertas. Fueron muy conocidas las reuniones que propiciaron el encuentro de discípulos que más tarde se convertirían en maestros, como Paul Ricoeur, Nicolai Berdiáev, Jeanne Parain-Vial, Jean Paul Sartre. ¿Quién hizo posible que durante años tuvieran lugar estos encuentros? Gabriel Marcel, nacido en París, en 1889 , formado en filosofía en la Sorbona, dramaturgo y compositor. Hasta su muerte, acaecida en 1973, Marcel fue además un viajero y conferenciante incansable, Premio Erasmus y Premio de la Paz del Comercio Librero Alemán.

La vida de Gabriel Marcel estuvo marcada por experiencias que lo diferenciarían de otros. Su padre, Henry Marcel, pensaba que a pesar de su imponente formación, no había sabido nunca establecer un vínculo que fuera más que el simple afecto que profesaba por su hijo. Su amada esposa, Laura Meyer, enfermó repentinamente y murió antes de cuarenta y ocho horas. Fue una pérdida que el propio Marcel entendió que su padre nunca superaría.

Para Gabriel, la pérdida de su madre supuso entrar en contacto, muy pronto, con la muerte de un ser amado. 
Gabriel Marcel fue un niño sensible, que percibió enseguida el peso de la soledad como hijo único. Quizá por esta razón, su tía Marguerite, hermana de su madre, asumió con plena conciencia el papel de protectora y nueva madre del niño. A pesar de que en ocasiones la relación era en cierta medida asfixiante, Marcel halló apoyo y alivio en la atención de su tía. Así, recuerda que en un paseo por el parque Monceau se dirigió a ella para interrogarla sobre el problema de la muerte. Ante la pregunta del pequeño, no pudo ofrecerle ninguna respuesta, sino que contestó con total sinceridad a partir de su postura de no creyente que no podía contestar porque "estamos en una completa ignorancia". Marcel dijo: "está bien, yo intentaré saberlo más adelante". ${ }^{1}$ De este modo se hizo patente el punto de partida de la indagación filosófica de Gabriel Marcel.

Como él mismo señaló en alguna ocasión, el signo bajo el que había desarrollado su pensamiento, tanto filosófico como dramático, había sido el de la muerte. Años más tarde, la muerte de una persona tierna y admirable, su compañera y esposa, Jacqueline Boegner, hizo más mella en su vida. Jacqueline era la hermana de un compañero de Marcel y su enlace fue una de las experiencias que más luz y serenidad le aportaron. Igualmente,

${ }^{1}$ Gabriel Marcel, Entretiens autour, 1976, Neuchâtel, Editions La Baconnière, p. 24. la muerte de su padre, su tía y otros familiares y conocidos supuso para Gabriel Marcel momentos de dolor. A pesar de ello, jamás se apagó la luz que proyectaba en su entorno.

También la muerte de los demás, de desconocidos, de otros cuyos rostros no vio nunca pero supo que habían existido tocó su alma. Basta recordar la labor que desempeñó junto con muchos otros compañeros en un servicio que organizó Cruz Roja francesa para atender a personas que buscaban a un familiar o amigo desaparecido. El servicio llevaba un registro con los datos de los soldados fallecidos en el campo de batalla. El dolor no solo era de estas personas, sino también de quienes los recibían. El número de desaparecidos aumentó inesperadamente hacia finales de agosto de 1914 y en el servicio se vieron desbordados. En esos momentos, Marcel fue consciente de que no podía adoptar otra postura que no fuera la de escuchar y atender a quienes recibía. Quería evitar a toda costa que se sintieran como si les hablara una máquina; por el contrario quería que tuvieran la sensación de que estaban ante otro ser humano, ante alguien que era capaz de sentir y sufrir con ellos, ya que

no es necesario decir que en la inmensa mayoría de los casos eran, a fin de cuentas, noticias de fallecimientos lo que dábamos. Yo recibía 
personalmente cada día a cientos de personas que venían a nosotros a suplicarnos que arrojáramos alguna luz en la noche en la que se debatían. En estas situaciones, las fichas dejaban de ser para mí simples menciones abstractas: era más bien una llamada desgarradora de aquel a quien tenía que dar respuesta. ${ }^{2}$

\section{La muerte del otro es mi dolor}

Si miramos a nuestro alrededor, parece que la muerte es solo la que aparece en la esquela del periódico que anuncia que un individuo ha fallecido. Es ese "alguien" que entra a partir de ese momento en la lista de las personas a las que ya no podré dirigirme para preguntar nada. La muerte se vuelve cotidiana. Transita por los periódicos, por las estaciones de radio, por las redes sociales sin que despierte ya en nosotros la capacidad de recogimiento y asombro que producía en nuestros antepasados.

Gabriel Marcel nos conduce a un terreno más exacto, se sitúa en la posición más concreta de su propia filosofía:

El Espíritu de verdad tiene también otro nombre, más revelador aún: es también espíritu de fidelidad; y lo que este espíritu reclama de nosotros, lo creo cada vez más firme-

${ }^{2}$ Marcel, En chemin, ver quel éveil?, 1971, París, Gallimard, p, 312. mente, es un rechazo explícito, una negación expresa de la muerte. La muerte de la que se trata aquí no es ni la muerte en general que no es más que una ficción, ni mi muerte en tanto que mía, como lo admitía Brunschvicg en el curso del debate que mantuvimos en el Congreso de Descartes. ${ }^{3}$

El debate al que hace referencia Marcel se dio en el Congreso de Descartes celebrado en 1937. Léon Brunschvicg reprochó a Marcel que se preocupara egoístamente por su propia muerte más que por la de cualquier otra persona. Marcel respondió sin vacilar lo más mínimo que lo que importaba en realidad no era su propia muerte ni la de quien le estaba hablando en ese momento, sino la de aquellos a quienes amamos. Los lazos de ternura y amor, de comprensión y compasión que nos unen en muchas ocasiones a los que nos rodean, hace que su desaparición aparezca como una lesión personal. Ante el abismo que se abre cuando un ser querido muere, se siente una conmoción diferente a la que me produce mi propio deber morir. Es en realidad la muerte de los seres a los que amamos la que sale al paso, son ellos los que

caen bajo nuestra mirada espiritual, solo a ellos nos es dado gustar

${ }^{3}$ Homo Viator, 2005, Salamanca, Sígueme, trad. de Juan Padilla Moreno, p. 159. 
y querer en tanto que seres, aun si nuestra religión en el sentido más amplio no solo nos permite, sino que nos recomienda, incluso nos prescribe extrapolar y reclamar que la luz está en todas partes, que el amor está en todas partes, que el Ser está en todas partes. ${ }^{4}$

Por ello hemos de estar atentos y ser conscientes del peligro que supone asumir que la muerte nos arrebata al ser que amamos para siempre y que hemos de claudicar ante la pérdida. Para Marcel, hacer esto implica una traición porque entregamos a la muerte a la persona. La muerte supone, es obvio, la desaparición física de la persona, pero no así su conciencia, su esencia, su identidad. Si nos duele es porque amamos y nos importa; si no olvidamos es porque seguimos amando y trascendemos así los límites de la muerte. El propio Marcel aporta un ejemplo cuando recurre a una de sus obras teatrales y repite las palabras de uno de sus personajes: "amar a un ser es decir: tú no morirás nunca". ${ }^{5}$ Para el autor, no son las palabras de un texto, sino que cobran vida propia porque rescatamos al ser amado ya fallecido del pasado para hacer que a través del recuerdo, viva para siempre.

\footnotetext{
${ }^{4}$ Loc. cit.

${ }^{5}$ Ibid.
}

\section{Dos formas de amor:} oblativo y posesivo

El amor es el elemento que hace que podamos salvarnos de la destrucción irrevocable de la muerte. Pero hay que ser cuidadosos, porque un exceso de amor puede convertirse en una prisión para la persona que sigue viviendo y falsifica el recuerdo de quien ya no está. Marcel distinguía entre amor oblativo y amor posesivo. Ese amor del que habla Marcel tampoco hace referencia al término que ha sido tan mal empleado que ha acabado por perder su significado más profundo. Siguiendo a un psiquiatra ginebrino, el doctor Stocker, Marcel habla de amor oblativo-amor heterocéntrico y de amor posesivo. ${ }^{6}$ Lo que realmente nos importa, aunque parezca lo contrario, es la muerte del ser amado. No es que rechace el sobrecogimiento que nos invade al pensar en la propia muerte. Es obvio que si reflexiono sobre mi muerte me angustio, me sobrecoge y me sobrepasa. En este caso, puedo negarme a la muerte. Para nuestro autor, es posible alcanzar la capacidad de "anestesiarnos" frente al dolor que provoca ser conscientes de nuestra propia muerte. Pero en el caso del ser amado nos resulta imposible decir que no nos impacta su muerte. El dolor por la muerte del ser amado está siempre presente, y aunque el duelo alivia en cierto modo ese

\footnotetext{
${ }^{6}$ Homo viator, p. 308.
} 
dolor, la pena no desaparece por completo. Marcel propone que el dolor por la muerte del ser amado viene de ese amor que se le ha profesado, de ese amor oblativo y no posesivo.

Marcel se vale de sus obras de teatro para diferenciarlos. En La capilla ardiente, el amor posesivo de una madre hace que considere que la que iba a ser la esposa de su hijo fallecido no debe rehacer su vida sentimental por respeto a la memoria del difunto. A su juicio - diríamos que erróneamente-, es una falta de respeto a la memoria de su hijo; pero en realidad lo que sucede es que el amor que siente por su hijo es posesivo y arrastra a los demás a que paguen sus consecuencias. No acontece lo mismo en el caso de El dardo y El signo de la cruz, donde los protagonistas se convierten en ejemplos de amor oblativo. Este amor además logra evitar que la persona pase de un tú a un él. El amor posesivo convierte a la persona amada en un objeto, y el control que se ejerce sobre ella hace que la relación se convierta en superflua. En cambio, el amor oblativo hace que se produzca el encuentro entre dos seres que entienden y sienten que se elevan por encima de esa posesión y el otro sigue siendo un tú, incluso si ha traspasado el abismo de la muerte.

\section{Más allá de la muerte: el amor en Viktor Frankl}

Si se observa desde un punto de vista amplio la vida de Viktor Frankl, se entiende que el amor fue la fuerza presente en momentos decisivos. Un ejemplo es una narración de Frankl en la que recuerda que cuando estaba por despertar, sin haber abierto los ojos todavía, percibió una sensación agradable y sosegada de protección y cariño. Al abrir los ojos vio a su padre, sonriendo e inclinado sobre él. ${ }^{7} \mathrm{La}$ familia fue el pilar fundamental para Frankl, en la que recibió y dio amor. Cuando la familia fue deportada, el amor se presentó con más fuerza. Frankl recuerda como prisionero que la desesperación era una amenaza siempre presente, la que con más facilidad podía arrastrarlo a suicidarse lanzándose contra las alambradas, pero el recuerdo de su madre (Frankl no se enteró sino hasta tiempo después de la muerte de ella y de su primera esposa Tilly Grosser), lo que lo impulsaba a seguir adelante.

También aparece en su obra el recuerdo de Tilly, a quien indudablemente Frankl amó profundamente. Fueron, junto con otra pareja, los últimos matrimonios que pudieron inscribirse en el registro civil judío. El

${ }^{7}$ Viktor Frankl, Lo que no está escrito en mis libros, 2003, Buenos Aires, San Pablo, trad. de Ingrid Ostrowski, p. 17. 
matrimonio Frankl Grosser fue deportado a los campos de concentración. De nuevo, el recuerdo de otra persona muy amada, su esposa, impulsó a Frankl a seguir adelante en los momentos más difíciles.

El amor lo alejó de la muerte, cuando presa del dolor y las peores calamidades, por unos instantes pensó en hacer como otros y lanzarse contra las alambradas electrificadas.

Tanto el amor que profesó a su familia como el de pareja son los dos puntos sobre los que hemos hecho descansar este tema en la obra de Viktor Frankl. Vamos a ver con más detalle la cuestión del amor en este autor. En una de sus obras, se leen, por ejemplo, unas breves páginas dedicadas a esta cuestión. ${ }^{8}$ Tratado con más profundidad también aparece en otro de sus libros, y a partir de estas páginas presentamos el concepto del amor en Viktor Frankl. ${ }^{9}$

$\mathrm{Al}$ igual que para Gabriel Marcel, para Viktor Frankl la muerte nos separa físicamente de aquellos a los que amamos o de los que nos aman. El dolor se hace presente; a veces se atenúa, mientras que en otras su presencia se hace más consciente. Lo que ni la muerte ni el dolor pueden impedir es que se haya amado y que se siga

${ }^{8}$ El hombre doliente, 2003, Barcelona, Herder, trad. de P.F.Valdés y A. Von Ritter-Zahony, pp. 92-97.

${ }^{9}$ Psicoanálisis y existencialismo, 2013, México, FCE, trad. de Carlos Silva y José Mendoza, pp. 196-263. amando, aunque el objeto de nuestro amor ya no esté con nosotros.

Frankl se sintió perdido durante un tiempo después de su liberación, cuanto tuvo que recomponer su vida, a pesar de las penalidades, a pesar de que perdió a sus padres, su hermano, su esposa y no pudo nunca saber si la criatura que Tilly llevaba en su seno era una niña o un niño.

El encuentro con la muerte y el amor

Como muchos que fueron liberados de los campos de concentración, Viktor Frankl rehizo su vida. Volvió a ejercer como médico psiquiatra, escribió otra vez y encontró a la persona a la que estaría unido hasta su muerte en 1997, Eleanor Schwindt, Elly, una enfermera que se convirtió en su segunda esposa.

Un encuentro casual hizo que Frankl pudiera recomponer de forma definitiva su vida, de nuevo gracias al amor. Un día, recién casado con Elly, Frankl regresó a casa y le narró a su esposa el encuentro con un desconocido que iba jugando con una pulsera. Con solo verla, Frankl la reconoció, porque precisamente Tilly, al pasar un día por una tienda, le señaló una piedra azul con cuatro continentes como si fuera oro. Frankl regresó, compró la piedra y una cadena para engarzarla y se la regaló a Tilly. Poco 
tiempo después fueron deportados a los campos de concentración. Cuando Viktor Frankl le contó al desconocido la historia de la pulsera, el hombre se la dio. Al llegar a casa, Frankl abrió su corazón a Elly y dejó escapar todo un torrente de emociones vividas en el tiempo que estuvo internado. Después, salió de casa y al regresar llevaba la pulsera a la que había añadido un corazón de oro en el que estaba grabado su número de prisionero por una parte y una "E", inicial del nombre de Elly. Esa pulsera representaba el amor incondicional que había profesado a su primera esposa, lo que vivió junto a ella, lo que la muerte jamás le podría ya arrebatar. Al mismo tiempo, era el objeto que aparecía como un puente nuevo con una persona a la que Frankl manifestó su amor y admiración más profundos, Elly, su segunda esposa. El amor lo había salvado una primera vez de la muerte, y de nuevo el amor, una vez liberado de los campos de concentración, fue el impulso que lo llevó a una nueva vida.

\section{Tríada trágica: dolor, culpa y muerte}

En muchas ocasiones el ser humano crea sus propias circunstancias, vive conforme las pautas que persigue, las que más anhela, y acaba triunfando. Pero en otras ocasiones los logros se ven truncados por la pérdida del trabajo y todas las consecuencias que se derivan, el fallecimiento de un ser amado, la aparición de una discapacidad física o psíquica que hace que otros dependan de nosotros o viceversa. Esta capacidad simultánea de sufrimiento y de logro es propia de todos los seres humanos, inclusive de aquellos que padecen el estigma de lo que se denomina "enfermedad mental", porque la enfermedad no destruye a la persona, sino que solo disminuye la posibilidad de comunicarse con los demás. El núcleo de la persona se mantiene a salvo en todo momento.

Frankl presentó los momentos en los que todo escapa a nuestro control y nos vemos enfrentados a dificultades como la tríada trágica: dolor, culpa y muerte. Así la define:

En efecto, no hay ninguna situación de la vida que realmente carezca de sentido. Esto tiene su origen en que los aspectos aparentemente negativos de la existencia humana, dolor, culpa y muerte, se juntan en particular en la tríada trágica y pueden transformarse en algo positivo, en una realización, con solo afrontarlos con la actitud y la tesitura correctas. ${ }^{10}$

Lo que causa la culpa, dice el psiquiatra vienés, es irreparable, pero es posible superarla gracias a una actitud

${ }^{10}$ La psicoterapia en la práctica médica, 2004, Buenos Aires, San Pablo, trad. de Cristóbal Piechocki y Beatriz Romero, p. 332. 
de verdadero arrepentimiento. Respecto al sufrimiento, supone la más importante oportunidad para imponer un sentido. Frankl aboga por no dejarse vencer, porque incluso en las más penosas circunstancias es posible mostrar que la vida tiene un sentido hasta la última exhalación. Aquí entran en juego los valores actitudinales, aquellos que contribuyen a realizar algo valioso en medio de las dificultades.

También ante la muerte es posible hallar un sentido. Con la muerte biológica termina todo proceso físico. Pero la biografía, lo vivido, lo amado y lo sufrido, las decisiones que tomamos y a las que renunciamos, quedan intactos, no desaparecen con la muerte. Permanece siempre intocable el ser así de la persona que ha muerto. Cabe preguntarse, entonces, qué sentido puede tener la vida, que ha de llegar a un fin, a un punto final; qué sentido se le puede dar a una existencia finita y temporal, en la que está presente esa tríada trágica compuesta por el dolor, el sufrimiento y la muerte. Para encontrar una respuesta debemos acudir, de nuevo, al amor.

\section{El amor nos hace seres ilimitados}

Como punto de partida, Frankl diferenció entre el atractivo corporal sexual de una persona, que produce lo que denomina "enamoramiento", y aquello verdaderamente importante, que es el amor.

Reducirse al atractivo físico de una persona es limitarla por un tiempo a aquello que resulta sugestivo, descartando lo que realmente tiene valor, que es el carácter único de la persona amada. El ser humano es más que eso. Entre muchas otras posibilidades, tenemos la capacidad de crear, de dar forma o lugar a algo que pervivirá mucho tiempo después de nuestro paso por este mundo. Es lo que Frankl denominó valores creativos. El amor también puede contribuir de alguna manera a estos valores. En este caso no sería algo activo, algo que concebimos nosotros, sino que más bien nos hace que soltemos las riendas, que nos olvidemos de tener que hacer algo por nuestra parte. Se trata de aquello que surge cuando somos amados. Con ello aparecen tres factores que caracterizan al amor:

1. Aquello que podemos ser. Todas nuestas capacidades y potenciales no solo entran en juego de forma activa, sino que en el amor surgen, se revelan cuando somos acogidos por el otro. Somos seres únicos, peculiares y singulares. A juicio de Frankl, el amor no es ningún "mérito" sino sencillamente una "gracia"."1

${ }^{11}$ Psicoanálisis y existencialismo, op. cit., p. 198. 
2. Aparte de "gracia" es también encanto. Esto tiene un significado muy importante, ya que para el amante, el amor hechiza al mundo, lo transfigura, lo dota de un valor adicional. ${ }^{12}$ Cuando alguien ama, su entrega se convierte en algo que no solo llega a la persona, sino que también él mismo se ve beneficiado porque

el cosmos entero gana, para él, en extensión y en profundidad de valor. Resplandece bajo la luz brillante de aquellos valores que solo el enamorado acierta a ver, pues el amor no hace al hombre ciego, como a veces se piensa, sino que, por el contrario, le abre los ojos y le aguza la mirada para percibir los valores. ${ }^{13}$

3. El tercer factor es la posibilidad 184 de manifestar el amor dando vida a un nuevo ser, que su vez será singular y único. Para Frankl, la vida no se limita a triunfar en el amor; además, el matrimonio no tiene como finalidad exclusiva la de tener hijos. Una mujer que no sea madre o un matrimonio que no tenga hijos pueden encontrar sentido en su vida a pesar de esta circunstancia.

El sentido de la vida en general no se reduce, como indica Frankl, al éxito alcanzado en el terreno profesio-

${ }^{12}$ Loc. cit.

${ }^{13}$ Ibid., p. 198. nal, social, académico o amoroso. De ser así, nos olvidamos de ver al ser humano como un todo compuesto por una parte biológica corporal, otra psicológica (como alma) y la más importante, la espiritual, que es la que queda a salvo de la enfermedad y la destrucción. Desde esta perspectiva, Frankl entiende que el amor no es enamoramiento, fase en la que se idealiza a la otra persona. Tampoco es aquello que resulta más atractivo a nivel físico o anímico de la otra persona. El verdadero amor va más allá. No es amar lo que el ser amado "tiene", ni "algo" que haya en él; no se ve un tipo de cuerpo capaz de excitar, ni tampoco un alma capaz de conmover, sino que ve al mismo ser humano, a la persona misma a quien ama como un ser incomparable e insustituible. ${ }^{14}$

Esto conduce con facilidad al siguiente paso. Porque no es solo que el amor se da cuando vemos más allá de lo corporal o de algún rasgo especial de la persona amada, sino que es la respuesta a la dureza que supone la muerte de los que queremos.

Así y solamente así puede comprenderse que el amor sea capaz de sobreponerse a la muerte del ser amado, de sobrevivir; solamente así se comprende que el amor puede ser

${ }^{14}$ Ibid., p. 201. 
"más fuerte" que la muerte, es decir, que la destrucción de la existencia del ser amado. ${ }^{15}$

Quien habla aquí es coherente con su pensamiento y sus palabras, porque la Segunda Guerra Mundial le arrebató a sus padres, a su hermano, a su primera esposa y a un hijo que no llegó a nacer. La vivencia lo lleva a reafirmarse en su convicción de que la muerte no puede vencer al ser humano. Sin decir su nombre, evoca al prisionero que no sabe si su madre vive o no y que a pesar de ello sigue manteniendo conversaciones en espíritu con ella.${ }^{16}$ Como señala líneas más adelante, el amor no requiere el cuerpo para manifestarse, porque en realidad de donde proviene es de la parte espiritual. Esta parte se expresa a través de lo corporal y lo psicológico. Aunque el cuerpo tiene una importancia destacada, el amor no se agota en lo físico: el amor auténtico no necesita, en sí, lo corporal ni para despertar ni para realizarse, pero se sirve de ello para ambas cosas. ${ }^{17}$ Esto significa, por lo tanto, que si con la muerte se produce la desaparición física de la persona a la que amamos, no se borra su ser, aquello que ha sido.

\footnotetext{
${ }^{15}$ Ibid., p. 203.

${ }^{16}$ Ibid., p. 205.

${ }^{17}$ Ibid., p. 207.
}

\section{La muerte también da sentido a la vida}

Para Frankl es la finitud de la vida del ser humano, su condición de mortal y finito, la que le da sentido a su existencia. Si no supiéramos que algún día hemos de morir, posiblemente siempre postergaríamos nuestras obligaciones, con consecuencias nefastas. Para Frankl es precisamente esa "limitación" la que da sentido a nuestro paso por el mundo. Para él, en realidad, lo que cuenta no es el tiempo que vivimos, sino lo que somos capaces de hacer con ese tiempo. Por larga que haya sido una vida, no significa que ha sido mejor que la de otra persona que vivió menos, pero que quizá logró más que la primera.

Saber que algún día moriremos nos empuja a asumir nuestra vida con mayor responsabilidad, porque somos como el escultor al que se le da una pieza de mármol para que la trabaje, aunque no sabe de cuánto tiempo dispone. De lo que se trata es de que al sonar la campana pueda decir que con independencia del tiempo que tuvo, su obra es tan hermosa como la de cualquier otro. La muerte nos hace ser responsables de nuestra vida debido a su carácter irreversible.

En realidad, lo importante es lo que se ha hecho en vida, porque aunque desaparezcamos físicamente, aquello que aportamos, dejamos, creamos 
o quedó pendiente se salva de la muerte. Para Frankl, todo lo que sufrimos, vivimos y amamos, las decisiones que tomamos, los errores que cometemos, aquello a lo que por una u otra razón renunciamos, todo queda en lo que llamó el "registro eterno". Más allá de la dimensión racional hay una especie de registro en el que queda grabada toda vivencia humana. Todo es pasajero, pero también es eterno. No somos nosotros quienes lo eternizamos, sino que esto se produce por sí solo:

Toda nuestra vida, todo lo que obramos, amamos y sufrimos se registra en el protocolo del Mundo. Se registra y se "conserva" en este protocolo. De manera que no es tal como lo ve un gran filósofo existencialista: que el mundo es como un manuscrito, un manuscrito que además está escrito en caracteres "cifrados". No, el mundo no es un manuscrito que debamos descifrar (y no podemos), el mundo es más bien un protocolo que debemos dictar. ${ }^{18}$

En nuestras manos está seleccionar lo que queremos que entre a formar parte de la eternidad. De esta manera, el mundo es un relato que escribimos día a día y así respondemos al mismo tiempo a los interrogantes que la propia vida nos plantea, como

${ }^{18}$ La voluntad de sentido, 2002, Barcelona, Herder, versión castellana de Fundación Arché bajo la dirección de Máximo J. Eckel, p. 55. sucede cuando la pregunta por la muerte hace acto de presencia en nuestra vida.

En una de las muchas entrevistas que concedió Frankl, su interlocutor, Franz Kreuzer, periodista austriaco, entre otras cosas le preguntó si se podría decir que pasamos a la eternidad. La respuesta fue: "Sí, se podría decir. Porque la eternidad no es un tiempo que se prolonga hacia el infinito, sino que está por encima del espacio y del tiempo". ${ }^{19}$

Esto nos impulsa a seguir con nuestras tareas cotidianas, tanto si es más fácil o más complejo. Es la capacidad de crear pero no para el futuro, sino del futuro al pasado. Nuestra responsabilidad ante la brevedad del tiempo de nuestra vida hace que escojamos lo que queremos que suceda en el futuro para poder recomponer nuestro pasado, porque en realidad es el pasado y no el futuro lo que nos ha de preocupar. Para comprenderlo, Frankl da el ejemplo de los graneros llenos que el granjero contempla con satisfacción después del esfuerzo. Quien ha llevado su vida sin dejarse condicionar por la finitud de la propia temporalidad, "ve los graneros llenos del pasado", ${ }^{20}$ su memoria, no llena de rastrojos, sino colmada de sentido por

${ }^{19}$ En el principio era el sentido, 2000, Barcelona, Paidós, p. 79.

${ }^{20}$ Logoterapia y análisis existencial, 2003, Barcelona, Herder, p. 151. 
la labor que ha llevado a cabo con tesón y paciencia, a pesar de que su obra sea desconocida para los demás, a pesar de que no pase a la posteridad con letras doradas.

Lo que importa es la calidad de la obra, como el escultor que ha de presentar su trabajo. No sabe cuándo deberá mostrarlo, no sabe tampoco para quién es ni el tiempo de que dispone. Lo que cuenta es que hasta dónde haya llegado, no haya renunciado en ningún momento a completarla. Nuestra existencia es

como un examen sobre nuestra capacidad, en el que no importa tanto que el trabajo llegue a terminarse como que sea valioso. El examinado tiene que estar dispuesto en todo momento a que suene la campana anunciando el final del tiempo puesto a su disposición; lo mismo ocurre en la vida al hombre: en el momento menos pensado puede sonar la voz que lo retire de la escena de los vivos. ${ }^{21}$

Vuelve a surgir la cuestión de si puede tener sentido la vida a pesar de su finitud y temporalidad, del sentido último de la vida. Esta es la respuesta que da Frankl:

No juzgamos el valor de una biografía por su extensión, por el número de páginas del libro, sino por la riqueza de su contenido. No cabe duda

${ }^{21}$ Psicoterapia y existencialismo, 2003, Barcelona, Herder, p.119. de que la vida heroica de un hombre muerto prematuramente encierra mayor contenido y mayor sentido que la existencia de cualquier filisteo que viva noventa años. Son muchas las sinfonías incompletas que figuran entre las más bellas. ${ }^{22}$

No es, pues, que el ser humano sea simplemente un ser cuya existencia es caduca y con un final inevitable, sino que es esa finitud la que da sentido a la existencia, con independencia del tiempo vivido. Es nuestra responsabilidad rescatar posibilidades del futuro para llenar nuestros graneros del pasado.

Así surge una nueva cuestión: ¿qué sucede con la persona que se encuentra próxima al final de su vida y ya no tiene futuro para dar forma a otras creaciones? Frankl dice que por una parte, si el hombre logra hacer algo realidad rescatándolo y situándolo en el pasado, entonces es el hombre el que se convierte a símismo en realidad, el que se "crea" a si mismo. Por otra parte, llegado el momento de la muerte, es cuando el ser humano se convierte en una realidad, porque sabemos que el haber existido es la forma más segura de ser. $^{23}$

También Kreuzer abordó la cuestión de querer borrar el sentido de la muerte de la siguiente manera: "es

${ }^{22}$ Psicoanálisis y existencialismo, p. 119.

${ }^{23}$ La voluntad de sentido, p. 57. 
decir, que una píldora que nos hiciera olvidarnos de la muerte también eliminaría el sentido de nuestra vida". ${ }^{24}$ Viktor Frankl estaba totalmente de acuerdo con Kreuzer. A su juicio, la consecuencia sería que nos haría inútiles. Nos despojaría de la capacidad de ser responsables y de actuar por nosotros mismos, de la necesidad que tenemos de vivir y aprovechar al máximo nuestro día, de poner en juego los valores y las actitudes en cualquier momento. La muerte era para Frank1 como la molestia que se siente cuando uno duerme profundamente y suena el despertador. Nos sentimos irritados por ese sonido que ha interrumpido lo bien que nos sentíamos. Pero la tarea del despertador es la de hacernos salir de esa pasividad para recordarnos que tenemos que incorporarnos a nuestra verdadera existencia. Lo mismo le sucede a la persona que se encuentra muy cerca del final de su propia vida, y ¿no nos asustamos también nosotros, los mortales, ante la muerte? ¿No malentendemos nosotros de qué modo la muerte nos despierta a la genuina, verdadera realidad dentro de nosotros?25 Aunque la mano que nos despierte lo haga con gesto de ternura, no dejamos de sentirla como algo que nos estorba. La muerte también la sentimos como algo terrible que nos sucede, y apenas

${ }^{24}$ En el principio era el sentido, p. 78.

${ }^{25}$ La voluntad de sentido, p. 57. sospechamos cuán buena es su intención para con nosotros... ${ }^{26}$ Por ejemplo, es posible que sea una oportunidad que no se repita para poder crear un sentido. Nos recuerda aquí el autor al sabio Hillel que aparece en el Antiguo Testamento y que hablaba así:
Si no lo hago yo, ¿quién lo hará? Y si no lo hago ahora, ¿cuándo tendré que hacerlo? Y si lo hago solo para mí, ¿qué soy yo? ${ }^{27}$

\section{Conclusiones}

La pregunta sobre la muerte sigue acuciando a los seres humanos. El poder de las nuevas tecnologías hace que se pueda retrasar casi sin límite, pero finalmente ha de llegar y de nuevo es ella la que vence. Nuestra estructura como seres humanos no deja de ser finita, mortal, temporal, frágil, siempre bajo la amenaza de la destrucción. La muerte, propia o ajena, molesta porque es una carga que se entromete y nos limita, no nos deja margen para actuar como quisiéramos. Por ello se transforma en la esquela del periódico que leemos de forma distante y olvidamos al cabo de unos segundos. Ante la primera impresión por el fallecimiento de alguien, enseguida se enfría ese asalto repentino que nos ha

\footnotetext{
${ }^{26}$ Ibid., p. 58.

${ }^{27}$ En el principio era el sentido, op. cit., p. 78.
} 
detenido por unos segundos el corazón. Parece que nos susurra que no olvidemos que también nuestro cuerpo y nuestros proyectos algún día dejarán de estar aquí. También la amenaza del olvido, de llegar demasiado pronto, o ¿por qué no?, también demasiado tarde al momento de la muerte, nos hace mirar hacia otro lado.

El duelo se medicaliza cada vez más, se controla y se limita a un plazo que, una vez cumplido, implica no poder hablar de la muerte ni sentir dolor. Con ello se niega directamente que nos incomoda y nos sentimos mal por la muerte de alguien porque lo queremos. Es precisamente el amor que sentimos por una persona lo que la hace única e irrepetible y la huella que nos deja es tal que no comprendemos por qué hemos de morir.

El bálsamo que tanto necesitamos en esos momentos en los que la muer- te se presenta como un zarpazo que nos arrebata sin miramiento alguno al ser que queremos es el amor. Fue el sustento que sirvió de brújula a Gabriel Marcel y a Viktor Frankl en los momentos en los que las tinieblas de la desesperanza se cernían sobre ellos. Frente a la marca que nos deja la ausencia de la persona que muere, el amor logra una transformación y hace que de nuevo esté presente. Quien muere antes que nosotros también rompe el vacío que nos inunda porque nos deja su legado, sus creaciones, sus proyectos. Con la muerte finaliza la existencia física, material, corporal, palpable y tangible, pero nuestros aciertos, logros, conquistas, quedan a salvo y para siempre en el registro eterno al que la muerte no puede acceder. El sello que nos asegura que ese registro es intocable es, sin duda, el amor. 
CITAM Derechos Reservados.

La reproducción total o parcial de este artículo se podrá hacer si el ITAM otorga la autorización previamente por escrito. 